\title{
A ORIGEM DAS PARCERIAS PÚBLICO-PRIVADA NA GOVERNANÇA GLOBAL DA EDUCAÇÃO*
}

\author{
SUSAN ROBERTSON \\ ANTONI VERGER ${ }^{* * *}$
}

\begin{abstract}
RESUMO: Durante a última década, a globalização da governança educacional por meio de parcerias público-privadas (PPP) tem gerado considerável debate quanto ao seu significado, propósito, status e resultados. Este debate é particularmente aquecido no setor da educação por causa da ampla aceitação da educação como atividade complexa, social e política que deve permanecer, em grande parte, se não totalmente, no setor público, servindo a interesses públicos. O artigo analisa a rápida expansão das parcerias público-privadas em educação (PPPE) articulada à introdução de regras de mercado no setor. Neste estudo nos concentramos sobre o papel de uma rede de desenvolvimento global, fundamental na globalização de um tipo particular de PPPE, indicando que a ideia de PPP encaixa-se em um projeto mais amplo de reconstituição da educação pública no âmbito do setor de serviços, a ser governada como parte da construção de uma sociedade de mercado.
\end{abstract}

Palavras-chave: Parcerias público-privadas. Globalização. Governança educacional. Empreendedores de políticas.

\section{THE EMERGENCE OF PUBLIC-PRIVATE PARTNERSHIPS}

\section{IN THE GLOBAL GOVERNANCE OF EDUCATION}

ABSTRACT: Over the past decade, the globalization and governing of education through Public Private Partnerships (PPPs) have generated considerable debate as to their meaning, purpose, status and outcomes. This debate is particularly heated in the education sector because of the widely-held view that education is a complex social and political activity that should remain largely, if not wholly, in the public sector serving public interests. The article analyses the rapid expansion of Education Public Private Partnerships (EPPPs) and the associated introduction of market rules into the education sector. We focus on

\footnotetext{
* Texto traduzido com autorização dos autores por Theresa Adrião e Romualdo Portela. Revisto por Márcia Teani.

* Doutora em Sociologia e professora de Sociologia da Educação na Graduate School of Education, Universidade de Bristol (Reino Unido).E-mail: S.L.Robertson@bristol.ac.uk

** Doutor em Sociologia e pesquisador sênior do Departamento de Sociologia da Universidade Autônoma de Barcelona (UAB), Espanha. E-mail: tverger@gmail.com
} 
the role of a key global development network in globalizing a particular kind of ePPPs, and show that the EPPP idea fits into a wider project of reconstituting public education as an education services industry to be governed as part of the construction of a market society.

Key words: Public-private partnerships. Globalization. Educational governance. Policy entrepreneurs.

\section{L'ORIGINE DES PARTENARIATS PUBLIC-PRIVES}

DANS LA GOUVERNANCE GLOBALE DE L'EDUCATION

RÉSUMÉ: Durant la dernière décennie, la globalisation de la gouvernance éducactive au moyen de Partenariats Public-Privés (PPPs) a occasionné un considérable débat quant à son sens, propos, statut et résultats. Ce débat est particulièrement intense dans le secteur de l'éducation à cause de la large acceptation de l'éducation comme activité complexe, sociale et politique qui doit rester en grande partie, sinon totalement, dans le secteur public servant des intérêts publics. L'article analyse la rapide expansion des Partenariats Public-Privés en Education (PPPEs) articulée avec l'introduction de règles de marché dans le secteur de l'éducation. Dans cette étude nous nous concentrons sur le rôle d'un réseau de développement global, fondamental dans la globalisation d'un type particulier de PPPEs, en indiquant que l'idée de PPP s'inscrit dans un projet plus ample de reconstitution de l'éducation publique dans l'environnement du secteur de services et vouée à être gouvernée comme partie de la construction d'une société de Marché.

Mots-clés: Partenariats public-privés. Globalisation. Gouvernance éducationnelle. Entrepreneurs en politiques.

\section{Introdução}

$\mathrm{D}$

urante a última década, a globalização e a governança da educação por meio das parcerias público-privadas (PPP) têm gerado considerável debate quanto ao seu significado, propósito, status e resultados. Este debate é particularmente aquecido no setor educacional devido ao ponto de vista largamente difundido da educação como atividade política e social complexa e que deve permanecer, em grande parte, se não na totalidade, no setor público e a serviço dos interesses públicos. A rápida expansão das parcerias público-privadas na educação (PPPE) envolve cada vez mais atores privados em uma faixa de atividade do setor público que inclui arenas tradicionais dos sistemas públicos de ensino: definição de políticas, oferta da educação, fiscalização e gestão escolar (cf. Hatcher, 2006; Ball, 2007; Bhanji, 2008; Saltman, 2010). Tal expansão merece, portanto, um exame detalhado.

Para alguns observadores, as PPPE são simplesmente uma nova e mais amigável face de uma antiga agenda de privatização (Hatcher, 2006), ao passo que, para outros, as PPPE apresentam-se como um meio inovador de financiamento da educação que se baseia no melhor do público e do privado com o potencial para resolver os profundos 
problemas sistêmicos dos sistemas de ensino, tais como acesso, qualidade e equidade (King, 2009). Seja qual for a veracidade de quaisquer das posições, as PPP não estão apenas "Cada vez mais profissionalizadas, técnicas e racionais" (Hodge et al., 2010, p. 3), elas também são parte de uma indústria em um ramo empresarial em rápido crescimento (Greve, 2010). No entanto, elas continuam a ser um enigma e seu status, como uma prática de governança contemporânea na educação, continua a ser controverso.

No centro deste debate estão questões em torno do que sejam as PPP e do por que se tornaram uma ferramenta de gestão favorecida por governos, empresas e agências de desenvolvimento internacional. Sob a égide da PPP, nos é claro que tem havido uma expansão muito rápida da atividade do setor privado no âmbito da esfera da educação pública; muito maior do que o imaginado no âmbito das políticas anteriores de liberalização do mercado que foram lançadas na década de 1980. Apesar de essas novas atividades privadas serem controversas, elas não são as únicas dimensões das PPP em questão. Governar a educação por meio das PPP é mais que uma questão de coordenar os serviços de educação, envolvendo agentes públicos e privados. No texto aqui apresentado, arguiremos que tais opções governamentais são centrais na constituição de tipos particulares de cidadãos (de mercado) (Stoer \& Magalhães, 2002), por um lado, e na reconstituição do setor da educação (como parte de uma indústria de serviços educacionais globais em rápido crescimento), por outro.

A fim de localizar e explicar a ascensão, importância e expansão global das PPP, retomamos, ainda que rapidamente, o avanço do liberalismo econômico, mais amplamente referido como o neoliberalismo, como um projeto político alternativo na década de 1980, e as transformações subsequentes que tiveram lugar na organização da vida social, política e econômica. Destinamos especial atenção à introdução do neoliberalismo (quase-mercados, concorrência e as formas nascentes de privatização) no setor da educação e à oposição e desafios com os quais seus principais proponentes foram confrontados na tentativa de reconstruir a educação de acordo com princípios do livre mercado. Em seguida, apresentamos o surgimento das PPPE, no início deste milênio, e as promessas sugeridas pela ideia de parceria. Por fim, nos concentramos no papel de uma rede de desenvolvimento global, fundamental para a globalização, e um tipo particular de PPPE, indicando como isto se encaixa em um projeto mais amplo que reconstitui a educação pública como uma indústria de serviços de educação a ser governada, como parte da construção de uma sociedade de mercado.

\section{O liberalismo econômico e a reestruturação da relação Estado- educação}

Para entender o significado das PPP e as alterações na relação entre o público e o privado na gestão da educação contemporânea, precisamos olhar para o início dos 
anos de 1970, para a crise do projeto de desenvolvimento capitalista do pós-guerra (um casamento entre liberalismo econômico e social-democracia) (Hobsbawm, 1994; Harvey, 2005), e para a posterior introdução da economia de livre mercado como o modo dominante de organização da vida política e social. Ideias de livre mercado circulam desde os anos de 1930, mas não tinham sido capazes de garantir apoio nos círculos políticos e na agenda da política.

Em vez disso, ideias keynesianas dominaram os esforços de reconstrução pósguerra, defendendo a gestão estatal das políticas econômicas e sociais, a fim de suavizar o ciclo de altos e baixos que caracterizou as economias capitalistas e de reparar as falhas do mercado. Neoliberais, por outro lado, argumentavam que a política keynesiana do dirigismo estatal tenderia a criar monopólios estatais com a "expulsão" do setor privado das áreas onde a concorrência e a submissão a riscos poderiam gerar ganhos de eficiência e inovação. Para os neoliberais, o papel apropriado para o Estado era criar e preservar um quadro institucional que garantisse condições para que o mercado funcione de forma eficaz (Harvey, 2005).

Como parte do projeto neoliberal, lançou-se, na década de 1980, um conjunto de ideias-chave com destaque para: a fragmentação das políticas estatais protecionistas, de modo a facilitar a livre movimentação do comércio, das finanças e do trabalho através das fronteiras nacionais (conhecida como desregulação); a implementação de políticas de concorrência entre os setores público e privado destinadas à criação de eficiência; a privatização de uma série de antigas atividades estatais e seu redimensionamento (envolvendo um processo dual de descentralização e recentralização). O estatuto especial das atividades do Estado como "serviços públicos" ou não seria mais aplicável ou necessitaria ser radicalmente repensado. Segundo afirmações de Leys (2003, p. 3), "As instituições do Estado foram reestruturadas com três objetivos principais: fazer com que o Estado servisse aos interesses dos negócios; remodelar suas operações internas sob a linha dos negócios e reduzir a exposição do governo à pressão política do eleitorado". Em círculos relacionados à política e ao desenvolvimento econômico, este conjunto de ideias veio a ser conhecido como Consenso de Washington (Williamson, 1993).

Esses objetivos foram, então, traduzidos em novos discursos e estratégias de gestão, levando Hood (1991) a cunhar a expressão "nova gestão pública" (NGP) para se referir a um grupo de elementos que incluiu metas de desempenho, a transferência do gerenciamento para os gestores, a especificação de padrões e indicadores, a alocação regida por resultados, auditoria e terceirização de uma série de atividades que haviam sido uma parte central do setor público. E enquanto os resultados do neoliberalismo, como um projeto político, variavam entre os países, o mesmo não ocorria com as suas características gerais e a forma de legitimação de suas intervenções. Mercados e concorrência, e o papel do setor privado em novas e antigas áreas 
de prestação de serviços (Ball, 2007), foram apresentados como "de interesse nacional", central para a competitividade econômica global, como um meio de superar a pobreza e a desaceleração econômica, e como base para a construção de economias baseadas no conhecimento.

No entanto, no início dos anos 1990, enquanto muitos falavam que a educação havia sido privatizada e mercantilizada, muito do esforço da reforma educacional nos países de alta renda centrou-se na introdução da concorrência e de políticas de escolha (mais conhecida como quase-mercados) para a governança da educação (Chubb \& Moe, 1988; Gewirtz, Ball \& Bowe, 1995), ao invés de privatização em linha direta (Dale, 1997). Nos EUA e Canadá, os interesses privados tenderam a assumir a forma de comercialização, tais como ter direitos exclusivos para vender refrigerantes, ou fornecer materiais curriculares gratuitos a fim de promover produtos específicos (Molnar, 2006).

Durante esse período, as principais agências internacionais e governamentais - Banco Mundial (BM), Fundo Monetário Internacional (FMI), Organização para a Cooperação e o Desenvolvimento Econômico (OCDE), United States Agency for International Development (Usaid) - desempenharam papéis cada vez mais instrumentais no avanço das ideias do livre mercado como base para o desenvolvimento. Em países de baixa renda, projetos políticos de matriz neoliberal avançaram por meio de políticas de ajuste estrutural propostos pelo BM/FMI (Samoff, 1994). Este repertório político, que incluía a descentralização, a privatização e a cobrança de taxas, teve consequências devastadoras não só na qualidade e na capacidade desses sistemas de ensino, mas também para as sociedades como um todo nas quais se inserem, tendo em vista a crescente polarização social e os níveis de desigualdade (Bonal, 2002; Ilon, 1994). A OCDE desenvolveu semelhante agenda neoliberal - embora, neste caso, destinada a países de alta renda (Rizvi \& Lingard, 2006) - descentralização, autonomia institucional (em oposição a formas burocráticas de organização) e introdução da escolha dos pais.

Se a perspectiva de governança voltou-se contra o Estado, sendo defendida por liberais de mercado, é importante reconhecer que hegemonias não se constroem a partir de conjuntos estreitos de interesses. Elas surgem da capacidade de se articular com uma gama de preocupações, alinhando-as com determinados tipos de soluções possíveis: neste caso, o mercado, em oposição ao Estado. Yeatman (1997) argumenta que a virada para o contratualismo, que emergiu do neoliberalismo, foi paradoxal na medida em que abriu a possibilidade de rever a base do contrato de bem-estar do Estado-social do pós-guerra, na qual o cidadão era homem, branco, empregado e chefe de família. No entanto, como aponta Hirsch (2003), muitos dos conceitos de governança que emergiram para garantir a coordenação dos serviços, tais como parcerias e redes de regulamentação, tendem a reduzir a democracia 
à negociação no seio da sociedade civil entre atores extremamente desiguais, ou simplesmente à mobilização participativa. O governo cedeu lugar à governança e a internacionalização do estado é, ao mesmo tempo, causa e efeito de uma reestruturação fundamental das relações de classe (Hirsch, 2003; Harvey, 2005; Sassen, 2006). Por isso, estudiosos como Harvey argumentam que o Estado competitivo e suas tendências de internacionalização foram o resultado da mobilização de poder bemsucedida por parte do Estado e de frações particulares (finanças); também o foram a liberalização da política do Estado e o ambiente regulatório que, por sua vez, aumentou a pressão sobre os sindicatos nacionais (Harvey, 2005). Como consequência, assiste-se a uma significativa reformulação das relações de classe, que surgiu como resultado desses processos, especialmente em benefício das elites empresariais e em detrimento dos trabalhadores e das classes médias.

Outro conjunto de dinâmicas do lado da demanda também foi percebido no setor da educação, como resultado de maior concorrência para mais e maiores credenciais escolares ou status social, a fim de garantir emprego em um mercado de trabalho global e cada vez mais competitivo. Brown cunhou dois termos que são úteis para os nossos propósitos: a ideologia da "parentocracia" e a ideia de um crescente "déficit de oportunidades" (Brown, 2000; Brown, 2006). Por "parentocracia", Brown (1990, p. 66) identifica o processo pelo qual a "(...) educação de uma criança é cada vez mais dependente da riqueza e dos desejos dos pais, em vez da capacidade e dos esforços da criança". A característica definidora da "parentocracia educacional" não é a quantidade de educação recebida, mas a base social sobre a qual a seleção educacional está organizada. Em outras palavras, uma educação adquirida em uma escola particular de alto status, ou em uma escola altamente seletiva com financiamento público (embora legitimada por políticas como a escolha da escola ou de escolarização com baixa mensalidade), ou em uma universidade altamente seletiva, apresenta um valor social significativamente maior do que aquela adquirida em uma escola que não é capaz de ser seletiva, ou cuja seleção não gera status. Conceitos de Brown nos ajudam a compreender por que as famílias investem consideráveis (e crescentes) montantes de seus recursos - dinheiro, tempo e custos de oportunidade - em escolher determinados tipos de experiências educativa e institucionais, aumentando experiências para garantir o acesso a oportunidades diminuídas em economias globalmente competitivas. Tais demandas exigem fornecedores específicos, entre os quais o próprio Estado. Brown (1990) argumenta que a educação tornou-se mais acessível e mais equitativa, resultado da oferta do Estado expandido e de sua política de igualdade de acesso e resultados. Uma terceira onda no desenvolvimento sócio-histórico da educação em economias ocidentais avançadas tornou-se evidente, resultando no afastamento da ideologia da meritocracia e aproximação com a ideologia da "parentocracia". Os pais, neste processo, tornam-se os responsáveis pela habilitação e realização do futuro de seus filhos. 
Eles procuram morar em vizinhanças corretas, particularmente se esta é a base da seleção, ou ainda frequentar as redes sociais adequadas. As famílias gastam somas consideráveis de suas rendas na compra de recursos potencializadores de status, como aulas particulares (por exemplo, disciplinas escolares, atividades culturais, idiomas), ou matriculando seus filhos em cursinhos ou outras formas do que Bray (2011) classifica como "escolarização oculta".

No entanto, no início de 1990, esta primeira onda de políticas pró-mercado, impulsionadas por governos e agências internacionais, começa a ser questionada, tanto por suas consequências deletérias para o desenvolvimento econômico e social, quanto por ser resultado da crescente oposição.

\section{"Parcerias": mediando ou fazendo o mercado?}

As "parcerias" surgiram no início de 1990 como um promissor mecanismo para minimizar os danos causados por formas anteriores de privatização, ainda que sem abandoná-las. Mais importante, as parcerias permitiram enquadramentos múltiplos e a realização de múltiplos interesses e múltiplos objetivos (Newman, 2001).

O renascimento das "parcerias" também se articulou a mudanças mais amplas na paisagem ideológica e conceitual da governança, em direção a uma "terceira via" entre o Estado e o mercado, como a de Blair, em seu "governo para a modernização" no Reino Unido (Newman, 2001). Elas foram um corretivo para a presença demasiada do Estado (keynesianismo), por um lado, e a ausência dele, por outro (privatização). Ao agir como uma ponte entre cada setor, as parcerias atuavam como um canal, permitindo o aproveitamento de valores de cada parceiro, a serem capitalizados no futuro.

O setor público chama a atenção para o interesse público, a administração e as relações de solidariedade (...). O setor privado é pensado para ser criativo e dinâmico, trazendo o acesso ao conhecimento de finanças, de tecnologias, de eficiência gerencial e do espírito empreendedor (...). A organização sem fins lucrativos, por sua vez, é forte em áreas que necessitam de compaixão e compromisso com as pessoas. (Rosenau, 2000, p. 218)

Tais opiniões foram defendidas por escritores, como Osborne e Gaebler (1992), cujo influente livro, Reinventando o governo, argumentava que as tendências monopolistas do governo não eram mais úteis em uma economia globalizada (1992). Em vez disso, os governos deveriam aprender a entender o que eles faziam de melhor: liderar a definição de políticas, ao invés de operacionalizá-las ou prestar diretamente os serviços; “(...) tal condição reforça a responsabilização pelo desempenho de qualidade: os fornecedores sabem que podem ser dispensados se sua qualidade cair; funcionários públicos sabem que não podem" (Osborne \& Gaebler, 1992, p. 35). No 
entanto, Osborne e Gaebler também tinham em mente um tipo diferente de serviço público, uma forma mais empreendedora que "Habitualmente utiliza recursos de novas maneiras para maximizar a produtividade e eficácia" (idem, ibid., p. xix). Ball e Youdell (2007) descrevem esta nova maneira como a privatização no governo, que se distingue da privatização do governo.

Bovaird (2004) aponta para outra fonte que explica a crescente importância das parcerias. Trata-se do trabalho de economistas como Oliver Williamson (1975) sobre os custos de transação associados à contratação; os altos custos das atividades associadas a contratos complexos, tais como desenhar, desenvolver, monitorar, entre outras. Significa dizer que seria muito melhor para uma empresa assumir todas estas atividades no seu interior, ao invés de fazê-lo por organizações externas, exceto no caso de contratos relacionais construídos na base de parceria e confiança. A literatura de gestão estratégica também lançou as bases para o paradigma de boa governança, sustentando aquilo que não foi mencionado como pós-Consenso de Washington (cf. Kooiman, 1993; Rhodes, 1997).

A abordagem da boa governança critica a excessiva atenção destinada à eficiência como critério único para determinar o "valor" para um investimento, uma vez que a preocupação com a "eficiência" pode muito rapidamente levar a danos à reputação, como práticas trabalhistas injustas, falta de transparência, resultados de má qualidade e assim por diante. Um foco na efetividade preocupa-se com resultados e estratégias (partilha de riscos, métodos inovadores etc.) implantadas para a realização destes resultados.

Ao final dos anos de 1990, as grandes agências internacionais do sistema das Nações Unidas, incluindo o Banco Mundial e OCDE e doadores bilaterais (tais como DFID, Usaid e Danida) (cf. Kirkemann \& Appelquist, 2008), começaram a concentrar-se nas parcerias, argumentando que, se os países buscavam alcançar as Metas de Desenvolvimento do Milênio, eles seriam obrigados a avançar na direção de um novo paradigma de desenvolvimento (Martin, 2000; Dunning, 2006). As parcerias também contaram com os dez princípios do Pacto Global das Nações Unidas lançado por seu diretor, Kofi Annan, em 1999 (Bull, 2010). De acordo com Annan, a nova ênfase pauta-se no mercado e no empreendedorismo, resultando de mudanças ideológicas no conjunto da economia política e apresentando-se como um meio para resolver antigos constrangimentos financeiros. Argumenta Bull (2010, p. 481): “As PPP foram (...) um meio das empresas se moverem na mesma direção dos Estados e das organizações multilaterais". Neste sentido, o pioneiro entre os organismos das Nações Unidas foi o Fundo das Nações Unidas para a Infância (Unicef), que desde muito cedo procurou financiamento no setor de negócios e propunha ações em colaboração (Bull, op. cit.).

Em 2004, a ONU lançou seu programa de PPP (Bull \& McNeil, 2007). Grandes corporações foram convidadas a adotar o Pacto Global em cooperação com a ONU 
como parte de seus compromissos de responsabilidade social (Bull, 2010). Ainda que as parcerias tivessem múltiplos propósitos, os partícipes compartilhavam o mesmo objetivo: combinar esforços de Estados, organizações multilaterais e setor privado (com e sem fins lucrativos, ONGs) na busca de objetivos comuns. Para Bull e McNeil (2007), as PPP, embora de forma desigual, transformaram o sistema multilateral.

Ainda que existam diferentes PPPE, que vão desde a construção, gestão e manutenção de infraestrutura até a mobilização de recursos, defesa de políticas, prestação de serviços e de operações (Ball, 2007; Bull, 2010), elas possuem uma base comum e um conjunto de ideias programáticas que representam a continuação, e não a moderação, do liberalismo econômico. Esta é também a posição de Linder (2000), ao analisar as PPP no contexto dos EUA, para quem, apesar de existirem múltiplos significados ou gramáticas para as parcerias (como reforma da gestão, regeneração moral e assim por diante), seus pontos de referência ideológica são a articulação do neoliberalismo com o neoconservadorismo. Mesmo distintos, esses dois pontos apresentam em comum uma aversão ao Estado: para os neoliberais, porque o Estado é ineficiente; para os neoconservadores, porque o Estado é perpetuamente sobrecarregado por demandas levantadas por aqueles que não merecem atenção.

A ideia das parcerias, portanto, parece agir como um mecanismo útil, não apenas por colocar diferentes atores juntos e, por isso, diferentes grupos e diferentes tipos de conhecimento, mas por intermediar, mais do que mitigar ou mediar, a privatização na e da educação. Ao fazer esta distinção, estamos de acordo com Ball (2007), para quem a privatização normalmente envolve uma variedade de processos e, por esta razão, seria mais apropriado pensar em privatizações.

\section{PPPE e globalização: os empreendedores da política e o making of de uma sociedade de mercado}

O surgimento de um discurso global sobre PPPEs tem sido particularmente acentuado em torno dos temas da educação para o desenvolvimento. Isso levanta a questão de como as ideias são articuladas e representadas. Nesta seção, examinamos o papel de um pequeno grupo de empreendedores de políticas e especialistas em educação que têm desempenhado um papel central na promoção de uma versão específica de PPPEs em âmbito global, mas é importante ressaltar que não necessariamente tenham sido efetivos na materialização e incorporação de suas ideias, dada a variedade de configurações nacionais.

Esta pequena rede de empreendedores de políticas e especialistas em educação localiza-se nos interstícios de uma seleta gama de organizações internacionais, empresas de consultoria transnacionais de educação e universidades globais - como o Banco Mundial, o Banco Asiático de Desenvolvimento (BAD), o International Finance 
Corporation (IFC), o Centro de Professores Britânicos (CfBT) e, mais recentemente, a Universidade de Harvard - e tem sido responsável por promover a ideia de PPPEs no interior do debate sobre desenvolvimento. ${ }^{1}$

Nos anos de 1990, representantes dessas organizações reuniram-se no grupo temático sobre Economia da Educação do Banco Mundial e abriram uma linha de pesquisa e discussões sobre formas e alternativas privadas de oferta educacional, inicialmente com foco na África Subsaariana. Em 2001, no contexto da IFC, esse mesmo grupo de especialistas lançou um manual sobre PPPs na educação. Os principais autores desta colaboração foram Norman LaRocque, então diretor corporativo de finanças da Empresa Anderson Consulting na Nova Zelândia, James Tooley, professor de Política de Educação no Reino Unido, e Michael Latham, assessor de Serviços Educacionais da CfBT, juntamente com Harry Patrinos, economista sênior de Educação do BM. Essas pessoas têm sido fundamentais para o avanço da agenda das PPPs na educação.

Essa rede de especialistas em educação está por trás das publicações mais conhecidas, dossiês e ferramentas sobre PPPEs, culminando no relatório amplamente divulgado pelo Banco Mundial, O Papel e o Impacto das PPPEs na Educação, lançado em 2009 (ver Tabela 1). A rede também está por trás da organização e do desenvolvimento de uma série de eventos nos quais a ideia das PPPEs tem sido discutida por governantes, políticos, agências doadoras, funcionários de organizações internacionais e acadêmicos. A rede é bastante estreita em seu escopo, mas muito coesa. Como observado nas publicações e eventos identificados, seus membros escrevem e falam em eventos e iniciativas uns dos outros (publicações, seminários, cursos, entre outros).

Tabela 1

\begin{tabular}{|c|c|c|c|}
\hline Organização & Ano & Título & Autores \\
\hline $\mathrm{BAD}$ e $\mathrm{BM}$ & 22000 & The New Social Policy Agenda in Asia & Y. Wang (editor) \\
\hline CIF & 22001 & Handbook on PPPs and Education & $\begin{array}{l}\text { N. LaRocque, J. } \\
\text { Tooley and M. } \\
\text { Latham }\end{array}$ \\
\hline CfBT & 22008 & Toolkit on PPPs and Education & M. Latham \\
\hline CfBT & 22008 & $\begin{array}{l}\text { PPPs in basic education. An International } \\
\text { Review }\end{array}$ & N. LaRocque \\
\hline $\mathrm{BM}$ e CIF & 22008 & $\begin{array}{l}\text { The evolving regulatory context for private } \\
\text { education in emerging economies }\end{array}$ & $\begin{array}{l}\text { J. Fielden and } \mathrm{N} . \\
\text { LaRocque }\end{array}$ \\
\hline
\end{tabular}




\begin{tabular}{|c|c|l|c|}
\hline CIF-Edinvest & 22009 & Public-Private Partnerships in Education & M. Latham \\
\hline BM & 22009 & The Role and impact of PPPs in education & $\begin{array}{l}\text { H. Patrinos, F. } \\
\text { Barrera-Osorio } \\
\text { and J. Guáqueta }\end{array}$ \\
\hline $\begin{array}{c}\text { UNICEF e } \\
\text { BAD }\end{array}$ & 22011 & $\begin{array}{l}\text { Non-State Providers and Public-Private } \\
\text { Partnerships in Education for the Poor }\end{array}$ & N. LaRocque \\
\hline
\end{tabular}

Notas do revisor: $\mathrm{BM}=$ Banco Mundial; $\mathrm{BAD}=$ Banco Asiático de Desenvolvimento; $\mathrm{CIF}=$ Corporação Internacional de finanças; CIF-Edinvest= Um fórum de investimento da CIF; CfBT ou CfBT Education Trust = Empresa de caridade que atua em parceria com o setor público de educação, seu nome significa Centro Britânico de Treinamento de Professores.

A principal premissa da rede é que “(...) A educação é um bem de consumo, e que o aluno é seu principal consumidor através dos pais" (IFC, 2001, p. 1). Disso decorre que, para os pais (e estudantes) escolherem, o setor de educação precisa estar organizado de forma a operar com a lógica de um mercado livre, o que inclui informações sobre a natureza da educação oferecida pelos vários fornecedores, incluindo sua qualidade; a vigência de incentivos que induzam ao desempenho esperado; a garantia de mecanismos de regulação que protejam os interesses dos investidores privados e assegurem uma concorrência leal entre os fornecedores, e um sistema de avaliação capaz de fornecer retorno para o sistema de informação, criando um círculo virtuoso.

No entanto, para esta rede de empreendedores de políticas, o papel do Estado na gestão da educação é importante para minimizar as falhas de mercado e para responder às preocupações de equidade. PPPEs são, portanto, o guarda-chuva perfeito, pois enquanto o propósito subjacente e as lógicas de gestão da educação são garantidos de acordo com a lógica de mercado, dada a presença do setor privado como responsável pela oferta, o Estado assegura o ambiente político favorável e, o mais importante, o seu financiamento. Como o Banco observa em seu texto principal sobre as PPPEs:

(...) A política do governo orienta e fornece financiamento, enquanto o setor privado oferece serviços de educação aos alunos. Em particular, os governos contratam prestadores privados para fornecer um serviço específico de uma quantidade definida e qualidade a um preço acordado para um período específico de tempo. Estes contratos incluem recompensas e sanções pelas quais o setor privado partilha os riscos financeiros na prestação de serviços públicos. (Patrinos et al., 2009, p. 1)

A legitimidade das PPPEs, como ferramenta de governança no desenvolvimento da educação, reside na sua promessa em resolver alguns dos problemas de difícil abordagem, enfrentados pela comunidade relacionada à temática do desenvolvimento. Isso inclui acesso à educação de qualidade, uma parte fundamental da 
agenda Educação para Todos e Metas de Desenvolvimento do Milênio, e redução da pobreza. No entanto, como mostra o Bretton Woods Project (2010), muitas vezes as PPPEs não favoreceram os muito pobres, e nem têm (no caso do IFC) favorecido países de baixa renda.

Os defensores das PPPEs salientam seu papel promissor na resolução dos problemas de qualidade pela via da reestruturação das condições de trabalho dos professores (revisão de contratos, adoção da concorrência e de incentivos) e da remoção do Estado na condução da educação, tendo em vista a caracterização de que é ele o principal responsável pela falta de qualidade, e sua substituição na gestão educacional por setores privados, compostos inclusive por atores internos ao sistema educacional, como professores, pais e alunos. Essas versões de PPPEs também reestruturam a administração das condições de trabalho dos professores, como o contrato de trabalho, incentivos e prêmios.

Uma política-chave associada à construção de PPPEs consiste na liberalização do setor educacional. Tal liberalização se destina a gerar um ambiente favorável ao surgimento de um setor privado mais ativo no campo educacional e estimular o surgimento de empresários no setor. A liberalização materializa-se na remoção de barreiras regulatórias para o desenvolvimento do setor privado, tais como a proibição da presença de empresas estrangeiras ou de instituições privadas atuando no setor educacional; vigência de tarifas para repatriar excedentes oriundos de atividades educacionais e definição de limites sobre taxas e mensalidades a serem cobradas pelas instituições com fins lucrativos, nacionais ou internacionais (Fielden \& LaRocque, 2008; Patrinos et al., 2009).

PPPEs implicam o afastamento do Estado da oferta direta da educação, mantendo seu foco no financiamento aos provedores (através de vales ou subsídios) e atuando na esfera da regulação e da avaliação dos serviços educacionais.

A maioria dos especialistas em PPPEs considera que o setor público não tem como operar com os incentivos necessários à oferta e que a provisão pública prejudica a concorrência e afeta negativamente a qualidade e o custo dos serviços de educação (IFC, 2001). No entanto, os especialistas não defendem a mercantilização pura ou a privatização da educação, mas consideram que o Estado deve continuar regulando e financiando a educação, embora - de preferência - por meio de fórmulas de financiamento à demanda. De fato, a regulação é a principal ferramenta com que os Estados contam para gerar um ambiente propício a parcerias e induzir resultados esperados (LaRocque, 2008). Além disso, no quadro de parcerias, os Estados devem avaliar e controlar o desempenho das escolas e premiar ou punir de acordo com seus resultados; alguns também sugerem que o Estado deva publicar as avaliações escolares para permitir que as famílias façam escolhas conscientes. Dessa forma, o fornecimento de informações (isto é, o desenvolvimento de estratégias eficazes de 
comunicação para informar os pais sobre a qualidade das escolas) se tornaria uma espécie de nova função do Estado.

Nesse sentido, para efeito de implementação, as ferramentas e os procedimentos propostos para as PPPEs são muito detalhados. Primeiro, seria recomendada a criação de uma agência autônoma para a garantia de qualidade da educação. Entre outras funções, esta agência deve especificar os resultados que as escolas devem alcançar e elaborar os indicadores de desempenho correspondentes, mas sem definir formas para seu alcance. Em paralelo, deve ser formada uma "agência de contratação de parcerias". Esta agência seria responsável pelo diálogo entre os setores privado e público e pela criação de um sistema de incentivos para os agentes envolvidos nas parcerias, em particular para os prestadores de serviços privados. Depois, deve ser organizado um processo de licitação para os prestadores privados. Este processo deve ser aberto, transparente e competitivo, e os requisitos de entrada para os prestadores privados devem ser claros. Uma vez que a PPPE esteja vigorando, os provedores podem receber pagamentos diferenciados em função de seu desempenho. No caso de baixo desempenho, os provedores podem ser punidos com a rescisão do contrato (LaRocque, 2008; IFC, 2001; Patrinos et al., 2009).

Proponentes das PPPEs também esperam que o Estado modifique sua cultura organizacional por meio da aprendizagem com o setor privado no nível gerencial. Especificamente, eles argumentam que as organizações do setor público devem aproveitar a sua participação nas estruturas de parceria para aprender com a cultura organizacional, as qualidades e os valores do setor privado, tais como flexibilidade, abertura às demandas sociais, incentivos à inovação e eficiência, entre outros (IFC, 2001; LaRocque, 2008).

Apesar das aparências, os proponentes das PPPEs não escondem um discurso anti-Estado, mas, ao mesmo tempo, não têm esperanças em desafiar sua autoridade na educação. Segundo eles, com as parcerias, o Estado deve se tornar menor, mas de fato mais forte, como na metáfora de Osborne e Gaebler (1992): “do remar para o pilotar". Evitando as responsabilidades menos importantes (como um entrevistado se referiu à oferta direta da educação), o Estado pode se concentrar no controle e planejamento estratégico do sistema de ensino. Resumindo, PPPEs não são contrárias à intervenção estatal, mas exigem a redefinição das funções do Estado na educação. A proposta parece paradoxal: por um lado, apoia soluções de mercado na educação, por outro, a intervenção do Estado é vista como crucial para garantir o funcionamento do mercado educacional.

Embora existam críticas que podem ser agrupadas na maneira como esses empreendedores de políticas conceituam a educação (como mercadoria ou bem privado), articulando causas e consequências (falência do Estado, preguiça dos professores e falta de incentivos) e um uso muito seletivo de evidências (ver também 
Verger [2012], para uma discussão sobre importantes aspectos a este respeito), para o nosso propósito, eles propiciam uma visão interessante sobre os esforços para promover uma versão particular das PPPEs. Embora esta versão das PPPEs seja clara, há uma variação na forma pela qual opera nos diferentes contextos; como uma estrutura de governança, PPPEs agora substituem a privatização. PPPE, do nosso ponto de vista, é uma metanarrativa que está contribuindo para a transformação do setor da educação, particularmente no que diz respeito à gama de atores privados e o concomitante aumento da autoridade privada.

\section{A ascensão de atores privados na construção da indústria das PPPEs}

Stephen Ball tem demonstrado (cf. Ball, 2007; 2008) que a(s) privatização(ões) da educação é (são) complexa(s), multifacetada(s) e interrelacionada(s). Tais processos envolvem o setor privado em todos os domínios da educação: elaboração de políticas e a divulgação de concepções que incorporaram os interesses do setor privado, colonizando a infraestrutura da política em uma extensão global. No entanto, como Greve (2010) observa, enquanto a literatura está cheia de evidências sobre como os governos agem para promover PPPEs, pouco se sabe a respeito do papel dos atores privados, incluindo organizações empresariais, no desenvolvimento dessas parcerias, e a maneira pelas quais contribuem, não apenas para a racionalização, industrialização, mas para a profissionalização deste modo de governar. De sorte que, garantir a inversão dessa política está cada vez mais difícil.

Uma indústria especializada (cada vez mais corporativa) surgiu em torno das PPPEs, especialmente nas economias desenvolvidas que levaram as PPPEs mais longe (por exemplo, Austrália, Reino Unido e EUA), e também em torno de serviços do sistema das Nações Unidas (Bull, 2010; Greve, 2010). Essa indústria, que de forma crescente exporta globalmente sua expertise, inclui um número crescente de atores privados, de fundações, de empresas especializadas em PPPEs, de firmas globais e locais de consultorias, de bancos, think tanks, ${ }^{2}$ de sites especializados, equipes de acompanhamento da mídia e escritórios de advocacia, que cada vez mais atuam como fontes de autoridade com orientação pró-mercado, "(...) Estabelecem regras, normas e instituições que orientam o comportamento dos participantes e afetam as oportunidades disponíveis para os outros" (Cutler et al., 1999, p. 4). Essa indústria de especialistas em PPPEs é parte de novo setor de serviços de educação, que inclui um número crescente de consultores que operam globalmente, organizações de gestão de educação, bem como fundações de ensino e filantropos engajados na modelagem da prática e da política educacionais (Saltman, 2010).

O envolvimento das fundações tem sido um fator no crescimento das PPPs (Bull, 2010), embora a atual crise econômica possa muito bem reduzir essa influência. 
O movimento em direção às PPPs no sistema da ONU, por exemplo, teve contribuições importantes de fundações (como a William e Flora Hewlett Foundation, Bill e Melinda Gates, Fundação das Nações Unidas), que, por sua vez, estão muitas vezes intimamente relacionadas aos negócios privados. Contudo, como observa Bull (op. cit.), a natureza das contribuições de fundações e empresas varia e, no caso de empresas privadas, as contribuições financeiras são muitas vezes marginais. Portanto, é difícil determinar onde a empresa contribui para o objetivo de desenvolvimento da ONU e onde ela simplesmente aproveita novas oportunidades de negócios.

Fundações também estão desempenhando um crescente papel na educação em geral (Saltman, 2010). Como mostra pesquisa de Scott (2009) nos EUA, “(...) Elas estão despejando grandes somas de dinheiro para a reforma da educação, visando especificamente a escolha da escola e a expansão da privatização" (Scott, 2009, p. 107). Estes novos (e velhos) filantropos funcionam de fato como uma coalizão, nos EUA, que visa influenciar os governos e as agendas de importantes líderes educacionais por mudança: concorrência, padronização, escolas charters, vouchers e testes de alto impacto. Eles são poderosos, na medida em que são fundamentais, ativos, condutores de ações políticas, pesquisas e defesa de suas posições. No entanto, esses filantropos mais recentes, como a Fundação Bill e Melinda Gates, Microsoft, a Fundação Robertson, a Fundação Donald e Doris Fisher (roupas Gap) ou a Família Wal-Mart, são diferentes das organizações filantrópicas mais antigas, como a Ford, Carnegie e Rockefeller Foundation, cuja origem remonta ao início do século 20. Os novos filantropos de "risco" salientam, simultaneamente, a melhoria da educação para crianças pobres ou minorias, financiam programas e redes que utilizam a linguagem do mercado para a mudança social, e esperaram agressivos retornos para seus investimentos (idem, ibid.). Scott (op. cit., p. 114-116) aponta para uma tensão importante nesta política de filantropia e proteção. Para ela:

A riqueza que vem em grande parte de políticas públicas favoráveis é direcionada principalmente para fundações isentas de impostos, nas quais curadores e filantropos diretamente moldam a política pública para os pobres sem o processo deliberativo aos quais as políticas de reforma escolar deveriam ser submetidas, se os recursos fossem públicos.

Um pequeno grupo de grandes e poderosas empresas de gestão global também têm grandes interesses nas PPPEs. Essas empresas fornecem conhecimentos sobre uma gama de aspectos relacionados à educação, à empresa e à política, desenvolvendo importante trabalho de pesquisa para os governos (atendendo a demandas terceirizadas, como resultado de reformas NGP), de gestão estratégica e de garantia de qualidade. No Reino Unido, por exemplo, a KPMG (2011) é parceira da City of London Corporation em uma Academia da cidade recém-criada em 2009. “A KPMG liderou o desenvolvimento da visão de educação, apoiou o desenvolvimento de uma abordagem de melhores práticas na prestação de serviços de TIC e de 
funções de suporte e ajudou no recrutamento de pessoal de excelência para garantir que os objetivos fossem atingidos" (KPMG, 2011). Ela integra um pequeno número de grandes empresas (como PricewaterhouseCoopers, Deloitte and Touche, Grant Thornton, Ernst and Young, McKinsey e Hay Group) envolvido em PPPs e que controla quase metade do mercado mundial de consultoria de gestão (Saint-Martin, 1998; Hodge, 2006). Juntas, essas empresas têm escritórios em mais de 140 países, espalhando-se por todo o mundo. Entre 1980 e 2003, o seu faturamento cresceu $800 \%$, de 3 bilhões de dólares para 120 bilhões em 2003 (Hodge, 2009). As estimativas para 2009/10 são colocadas em 192 bilhões de dólares. Todas têm grandes portfólios educacionais. "Por expertise na condução do desenvolvimento dos quadros jurídicos sobre PPPs e a prática real em países líderes, as empresas de consultoria global, dado o seu conhecimento superior de como as PPPs estão progredindo, têm poucos rivais" (Greve, 2010, p. 506).

Para Saint-Martin não foi apenas a ascensão do NGP o fator responsável por este aumento. Ele também resulta da abertura dos governos para esse tipo de expertise (conhecimento econômico/contábil) e da permeabilidade do setor a especialistas externos: "Há uma relação estreita entre o desenvolvimento de um determinado campo de conhecimento social, no nosso caso consultoria de gestão, e a abertura das instituições do Estado para o uso desse conhecimento" (Saint-Martin, 1998, p. 325). Nesse contexto é que as agências de desenvolvimento, tais como o Banco Mundial, IFC, Asia Development Bank e consultores das empresas, desempenham um papel crítico, não só no moldar as condições para a oferta de educação, mas na liberalização do mercado e na constituição de políticas e marcos regulatórios. "Consultocracia" é o termo usado para descrever o poder de consultores no assessoramento de governos e na definição das políticas governamentais. Segundo Hodge (2006, p. 99), a preocupação expressa através deste rótulo “é que os interesses dos consultores, que maximizam os lucros de gestão, podem se tornar os principais determinantes da política gerencialista". Dado que esses consultores são, em alguns casos, também os advogados (cf. Lovells \& Lee, 2009) e auditores (Greve, 2010) das PPPs, é difícil não concluir que algumas dessas relações de consultoria levantam importantes preocupações sobre conflitos de transparência, interesse e responsabilidade.

Há uma vasta e crescente gama de empresas globais de educação que vai desde consultorias como o Cambridge Education, Organizações de Gestão de Ensino (por exemplo, as que operam as escolas charters nos EUA ou as Academias, no Unido Reino), corporações educacionais como Laureate, Cisco Systems, Devry, Bridgewater, Edison Schools e grandes conglomerados de empresas que incluem negócios em educação, como o Apollo Global. Todos consideram o setor da Educação como um campo para potenciais investimentos em serviços, desde que sejam estabelecidas condições para realização de lucro (ver, entre outros, Ball, 2007; Saltman, 2010; Hentschke, Lechuga 
\& Tierney, 2010). Isso significa escolher segmentos (avaliação em larga escala, aulas particulares, etc.) que garantam maiores retornos (Hentschke, 2007).

Como podemos avaliar o rápido crescimento dos atores privados e seus interesses em um setor como a Educação? O trabalho de Cutler sobre as implicações legais da indefinição da separação entre os poderes público e privado é convincente. Ela não apenas argumenta, como Gill (2003), que os direitos privilegiados da cidadania e representação são transferidos ao capital corporativo, mas também afirma que, conforme o Estado se despe de atividades que tradicionalmente estiveram associadas ao setor público e ao interesse público, podemos ver uma tendência ascendente na gestão dos assuntos nacionais, regionais e globais de agentes econômicos e não estatais/políticos (Cutler et al., 1999). Cutler considera isso como o surgimento da "autoridade privada", isto é, quando um indivíduo ou organização tem o poder de decisão sobre uma questão particular (idem, ibid., p. 5). No setor da Educação, a cessão, por parte do Estado, do poder para tomar decisões (como a forma de enquadrar a base regulatória e operacional da atividade educativa) aos atores econômicos (tais como empresas de educação, empresas de consultoria, filantropos de risco) ou àqueles que fazem a licitação e negociação (como o Banco Mundial, o IFC) representa uma transferência da autoridade do público para o domínio privado e do âmbito nacional para o supranacional. Isto tem implicações significativas para a educação, para as sociedades e para a democracia (Crouch, 2011).

\section{Observações finais: rumo a um estudo crítico sobre PPPs na educação}

Nossa preocupação neste artigo foi concentrar-nos na gestão da educação por meio das PPPEs, com particular atenção para as maneiras pelas quais uma política global, com atores e consultores privados, está remodelando o campo do desenvolvimento. É evidente, como Ball (2007) mostrou, que há abalos sísmicos ocorrendo no setor da educação que merecem investigação detalhada e discussão pública. Em relação ao Reino Unido, Ball (op. cit., p. 39-40) afirma que: “A 'reforma' do setor de serviços públicos é uma oportunidade de lucro enorme para o novo negócio (...). A terceirização dos serviços educacionais movimenta ao menos 1,5 bilhões de libras esterlinas ao ano". Contudo, o que frisamos aqui é a maneira pela qual uma determinada concepção de educação está sendo globalizada e gerida, e que, longe de ser um mecanismo para diminuir o liberalismo econômico, aparentemente as PPPEs permitiram seu rápido avanço, dado que o setor privado está agora profundamente enraizado no coração dos serviços públicos educacionais, em todos os níveis, desde a política e a pesquisa até a aprendizagem nas salas de aula.

Lembrando Santos (2004, p. 149), entende-se globalização como “Um processo pelo qual uma determinada entidade atinge o globo, pelo alargamento de seu 
âmbito próprio e, ao fazê-lo, desenvolve a capacidade ou a prerrogativa de nomear como 'local' todas as entidades rivais". Vendo a globalização das parcerias público-privadas na educação dessa maneira, pela qual o localismo procura tornar-se hegemônico, lembramos que as PPPEs têm sua gênese em um determinado lugar e tempo. A globalização das parcerias público-privadas na educação é um resultado (ainda que muito importante) de processos associados ao neoliberalismo e à globalização econômica: como o aumento da porosidade das fronteiras institucionais e nacionais, o colapso da divisão entre o Estado/público e outros atores não estatais/ privados, a explosão do número de agentes e projetos operacionais, constituídos em escalas global e regional. Como podemos ver, essas dinâmicas resultam na transformação estrutural do nacional, enquanto o Estado se internacionaliza e o global penetra na esfera nacional (Sassen, 2006). Em síntese, as PPPEs são mecanismos e resultados que estão transformando o setor.

Essas transformações têm implicações importantes para o contrato social entre educação e Estado e, em particular, para a educação como bem social complexo. Empreendimento que demanda questionamentos fortes e respostas robustas, como, por exemplo, quem está envolvido na formulação dos problemas da educação e de sua governança e por que (e por quem) seriam as PPPEs o mecanismo mais indicado como solução? Quais são os efeitos dessas políticas e programas sobre as oportunidades educacionais e os resultados num sentido distributivo, de reconhecimento e relacional? E com base em que os diferentes tipos de atores (indivíduos e organizações, públicas e privadas, estatais e não estatais) participam ou não dessas iniciativas e vivenciam as consequências que lhe seguem?

Tais questões trazem à tona as implicações do enfraquecimento do controle central pelo governo e do como e onde as preocupações sobre a legitimidade dos processos e produtos podem ser abordadas. Elas também chamam nossa atenção para as formas pelas quais o controle sobre os recursos epistêmicos (Jayasuriya, 2008) - como vemos quando organismos internacionais e consultores remodelam a estrutura regulatória do Estado - permite que certos atores determinem a natureza e a configuração institucional por meio da qual a prestação de contas ocorre. A globalização das PPPs, como um instrumento de gestão de setores e assuntos educacionais, precisa ser cuidadosamente examinada, ressaltando o cuidado em não entendê-las como ferramentas simplesmente técnicas. Isto elas não são. PPPEs são, fundamentalmente, relações sociais e econômicas (Weihe, 2010), envolvem questões de poder, autoridade, legitimidade, responsabilidade e igualdade, e não apenas mecanismos de opção com base no mercado e em ganhos de eficiência (Jayasuriya, 2008).

Em relação ao assunto, repetimos Stoer e Magalhães (2002), segundo os quais, quando o novo contrato social entre o Estado e seus cidadãos é mediado por relações 
de mercado, o que está sendo constituído é um sujeito como consumidor e não um sujeito que opera no âmbito do público/político.

O trabalho de Fraser (2005) sobre a justiça social é particularmente útil aqui. Fraser desenvolve uma abordagem em três frentes para a justiça social: redistribuição (econômica), reconhecimento (cultural) e representação (política). Para a autora, justiça significa a paridade de participação, o que requer arranjos sociais que permitam que todos participem como pares na vida social (Fraser, 2005). Ela defende uma terceira dimensão de justiça social, focada na política, isto é, na representação (idem, ibid.). Como a autora observa, as dinâmicas associadas à globalização têm desafiado a abordagem keynesiana, levantando questões importantes em torno da natureza da jurisdição do Estado nacional, das decisões sobre estruturas de contestação e reclamações e como tais reivindicações devem ser adjudicadas. Em outras palavras, a adesão e os procedimentos são fundamentais para a dimensão política da justiça social.

Então, como fazer as PPPs educacionais equânimes em termos de justiça social? Obviamente, não se podem adotar juízos a priori, isto é, que em todos os casos as parcerias público-privadas são por si só soluções políticas boas, ruins ou neutras. Muito depende de como e por quem as categorias-chaves público/privada/parceria e educação são criadas, representadas e materializadas; como ordenam a vida social; como ativam ou desativam a participação na vida social e como são estabelecidas formas de prestação de contas. Como sugerido neste texto, o quadro adotado pelos empresários globais vinculados às PPPEs é fundamentado em lógicas e formas de prestação de contas baseadas no mercado, ao invés de possuir uma orientação pública, na qual o único modo viável de reconhecimento é ser consumidor, ao invés de ser um sujeito social e político. Isto representa uma visão empobrecida da educação como atividade social e prejudica a capacidade dos sujeitos sociais de serem reflexivos, na medida em que os limita e os define primeiramente como agentes econômicos, cujas ações são exclusivamente enquadradas em relações de mercado.

Finalmente, como argumenta Jayasuriya (2008), quando a governança está distribuída em vários locais, tanto a governança das PPPs quanto das PPPEs, como ferramenta de gestão do setor da educação, torna-se problemática. Quem é a autoridade relevante? Quem é afetado pelas decisões de vários governos, empresas transnacionais, fundações, agências internacionais e consultores? Quem deve ser procurado para prestar contas? É o discurso gerencial apropriado para a distribuição de um bem público como a educação? A gestão, com foco em resultados e na eficiência, é compatível com a complexidade dos processos educacionais? Esperamos que nosso artigo tenha contribuído para o aprofundamento dessa área de investigação, fornecendo recursos por meio dos quais se possa envolver outras pessoas em um debate sobre este tópico de suma importância. 


\section{Notas}

1. CfBT é uma consultora do Reino Unido que oferece internacionalmente uma variedade de serviços de educação.

2. N. do T.: O termo se refere a organizações privadas que atuam com vistas a influir na agenda das políticas públicas, combinando pesquisas direcionadas a fundamentar posições políticas e divulgação na mídia.

\section{Referências}

ARENDT, H. The human condition. Chicago: University of Chicago, 1958.

BALL, S.J. Education plc: understanding private sector participation in public sector education. New York: Routledge, 2007.

BALL, S.J. New philanthropy, new networks and new governance in education. Political Studies, Surrey, v. 56, n. 4, p. 747-765, 2008.

BALL, S.J.; YOUDELL, D. Hidden privatisation in public education. Preliminary report. Education International 5th World Congress, University of London, 2007.

BHANJI, Z. Transnational corporations in education: filling the governance gap through new social norms and market multilateralism? Globalisation, Societies and Education, New York, v. 6, n. 1, p. 55-73, 2008.

BONAL, X. Plus ça change... The World Bank Global Education Policy and the PostWashington Consensus. International Studies in Sociology of Educational, v. 12, n. 1, p. 3-21, 2002.

BOVAIRD, T. Public-private partnerships: from contested concepts to prevalent practice International Review of Administrative Science, n. 70, p. 199-215, 2004.

BRAY, M. The challenge of shadow education: private tutoring and its implications for policymakers in Europe. Brussels: Nesse; DGEAC, 2011.

BROWN, P. The third wave: education and the ideology of parentocracy. British Journal of Sociology of Education, London, v. 11, n. 1, p. 65-85, 1990.

BROWN, P. The globalization of positional competition. Sociology, v. 34, n. 4, p. 633-53, 2000.

BROWN, P. The opportunity trap. In: LAUDER, H. et al. (Org.). Education, globalization and social change. Oxford: Oxford University, 2006.

BULL, B. Public-private-partnerships: the United Nations experience. In: HODGE, G.; GREVE, C.; BOARDMAN, A. (Org.). International handbook on public-private partnerships. Cheltenham: Edward Elgar, 2010. 
BULL, B.; McNEILL, D. Development issues in global governance, public-private partnerships and market multilateralism. London; New York: Routledge, 2007.

CHUBB, J.; MOE, T. Politics, markets and the organisation of schools. American Political Science Review, Baltimore, v. 82, p. 1065-1087, 1988.

CROUCH, C. The strange non-death of neoliberalism. Cambridge: Polity, 2011.

CUTLER, A.C., HAUFLTER, V.; PORTER, T. Private authority and international affairs. New York: State University of New York, 1999.

DALE, R. The state and the governance of education: an analysis of the restructuring of the state-education relationship. In: HALSEY, A.H. et al. (Ed.). Education, culture, economy and society. Oxford: Oxford University Press, 1997.

DUNNING, J. Towards a new paradigm of development: implications for the determinants of international business. Transnational Corporations, New York, v. 15, n. 1, p. 173-227, 2006.

FIELDEN, J.; LAROCQUE, N. The evolving regulatory context for private education in emerging economies. Washington DC: World Bank, 2008.

FRASER, N. Reframing justice in a globalising world. New Left Review, London, n. 36, nov./dec. 2005.

GEWIRTZ, S.; BALL, S.; BOWE, R. Markets, choice and equity in education. Basingstoke: Open University, 1995.

GILL, S. Power and resistance in the New World Order. London: Palgrave, 2003.

GREVE, C. The global public-private partnership industry. In: HODGE, G.; GREVE, C.; BOARDMAN, A. (Org.). International handbook on public-private partnerships. Cheltenham: Edward Elgar, 2010.

HARVEY, D. A brief history of neoliberalism. Oxford: Oxford University, 2005.

HATCHER, R. Privatization and sponsorship: the re-agenting of the school system in England. Journal of Education Policy, London, v. 21, n. 5, p. 599-619, 2006.

HENTSCHKE, G. Characteristics of growth in the education industry: illustrations from US education businesses. In: MARTENS, K.; RUSCONI, A.; LEUZE, K. (Org.). New arenas of education governance. Basingstoke; New York: Palgrave, 2007.

HENTSCHKE, G.; LECHUGA, V.; TIERNEY, W. (Org.). For-profit colleges and universities. Virginia: Stylus, 2010.

HOBSBAWM, E. Age of extremes: the short twentieth century 1914-1991. London: Abacus, 1994. 
HODGE, G. Delivering performance improvements through public private partnerships: defining and evaluating a phenomenon. In: INSTITUTE OF PUBLIC ADMINISTRATION (IPA). International Conference on Administrative Development: towards excellence in public sector performance. Riyadh, 2009.

HODGE, G.; GREVE, C.; BOARMAN, A. Introduction: the PPP phenomenon and its evaluation, In: HODGE, G.; GREVE, C.; BOARMAN, A. (Org.). International handbook on public-private partnerships. Cheltenham: Edward Elgar, 2010.

HOOD, C. A public management for all seasons? Public Administration, London, v. 69, p. 3-19, 1991.

ILON, L. Structural adjustment and education: adapting to a growing global market. International Journal of Educational Development, v. 14, n. 2, p. 95-108, 1994.

INTERNATIONAL FINANCE CORPORATION (IFC). Handbook on PPPs and Education. Washington, DC: IFC, 2001.

JAYASURIYA, K. Retailing governance: the rise of accountability communities. Policy Brief, n. 2, June 2008.

KING, E. Foreword. In: PATRINOS, H.; BARRERA-OSORIO, F.; GUAQUETA, J. (Org.). The role and impact of public private partnerships in education. Washington, DC: World Bank, 2009.

KIRKEMANN, P.; APPELQUIST, M-L. Evaluation study: Public Private Partnership Programme. Taastrup: Nordic Consulting Company, 2008.

KOOIMAN, J. (Ed.). Modern governance: new government-society interactions. London: Sage, 1993.

KPMG. The city academy hackney: values and success. London: KPMG, 2011.

LAROCQUE. PPPs in basic education: an international review. London: CFBT, 2008.

LEYS, C. Market driven politics. New York: Verso, 2003.

LINDER, S. Coming to terms with the public-private partnership: a grammar of multiple meanings. American Behavioral Scientist, Princeton, v. 43, n. 1, p. 35, 1999.

LORANGE, P.; ROOS, I. Strategic alliances: formation, implementation and evolution. Oxford: Blackwells, 1992.

LOVELLS LEE \& LEE. PPP Projects in the Education Sector: key principles. [online], 2009. Disponível em: <http://www.hoganlovells.de/files/Publication/bb9e9af9-213c4568-87c0-769e1c3e069a/Presentation/publicationattachment/94598918-0d93-4526- 
a06b-86abc1d630fb/pppprojectsintheeducationsector-keyprinciples.pdf>. Acesso em: 6 out. 2010.

MARTIN, B. New leaf or fig leaf: the challenge of the New Washington Consensus, Bretton Woods Project and Public Services International. 2000. Disponível em: $<$ www.brettonwoodsproject.org/topic/knowledgebank/newleaf/newleaf_or_figleaf. pdf $>$. Acesso em: $1^{\circ}$ jul. 2006.

MOLNAR, A. The commercial transformation of public education, Journal of Education Policy, London, v. 21, n. 5, p. 621-40, 2006.

MUNDY, K. Education for all and the new development compact. International Review of Education, Hamburg, v. 52, n. 1, p. 23-48, 2006.

NEWMAN, J. Modernising governance, London: Sage, 2001.

OSBORNE, D.; GAEBLER, T. Reinventing government: how the entrepreneurial spirit is transforming the public sector. New York: Plume, 1992.

PATRINOS, H.; BARRERA-OSORIO, F.; GUAQUETA, J. The role and impact of public private partnerships in education. Washington, DC: World Bank, 2009.

RHODES, R.A.W. From marketisation to diplomacy: it's the mix that matters. Australian Journal of Public Administration, v. 56, n. 2, p. 40-53, 1997.

RIZVI, F.; LINGARD, B. Globalization and the changing nature of the OECD's educational work. In: LAUDER, H. et al. (Org.). Education, globalization and social change. Oxford: Oxford University, 2006.

ROSENAU, P.V. Public-private policy partnerships. Cambridge, Mass.: MIT, 2000.

RUGGIE, J. Multilateralism: the autonomy of an institution. International Organisation, v. 46, n. 3, p. 561-598, 1992.

SAINT-MARTIN, D. The new managerialism and the policy influence of consultants in government: an historical-institutionalist analysis of Britain, Canada and France. Governance: an International Journal of Policy and Administration, Oxford, v. 11, n. 3, p. 319-356, 1998.

SALTMAN, K. The gift of education: public education and venture philanthropy. New York: Palgrave, 2010.

SAMOFF, J. Coping with crisis: austerity, adjustment and human resources. London; New York: Cassell; Unesco, 1994.

SANTOS, B.S. Interview with Boaventura de Sousa Santos. Globalisation, Societies and Education, New York, v. 2, n. 2, p. 147-160, 2004. 
SASSEN, S. Territory, authority, rights. Princeton: Princeton University, 2006.

SCOTT, J. The politics of venture philanthropy in school charter policy and advocacy. Educational Policy, n. 23, p. 106-136, 2009.

STOER, S.; MAGALHAES, A. The reconfiguration of the modern social contract: new forms of citizenship and education. European Educational Research Journal, v. 1, n. 4, p. 692-705, 2002.

VERGER, A. Framing and selling global education policy: the promotion of publicprivate partnerships for education in low-income contexts. Journal of Education Policy, London, v. 27, n. 1, p. 109-130, 2012.

WEIHE, G. Toward a process perspective in public-private-partnerships. In: HODGE, G.; GREVE, C.; BOARDMAN, A. (Org.). International handbook on public-private partnerships. Cheltenham: Edward Elgar, 2010.

WETTENHALL, R. The rhetoric and reality of public-private partnerships. Public Organization Review, v. 3, n. 1, p. 77-107, 2003.

WILLIAMSON, J. Democracy and the Washington consensus. World Development, Oxford, v. 21, p. 1329-1336, 1993.

WILLIAMSON, O. Markets and hierarchies: analysis and antitrust implications. New York: Free, 1975.

WORLD BANK. Lifelong learning for a global knowledge economy. Washington, DC: World Bank, 2003.

YEATMAN, A. Contract, status and personhood. In: DAVIS, G.; SULLIVAN, B.; YEATMAN, A. (Org.). The new contractualism. Sydney: MacMillan, 1997.

Recebido em 29 de maio de 2012.

Aprovado em 21 de agosto de 2012. 